\title{
Transforming Energy Usage: It's Not Only about Solar
}

\author{
Melissa Matlock \\ GRID Alternatives, Riverside, USA \\ Email: mmatlock@gridalternatives.org
}

Received 4 April 2014; revised 4 May 2014; accepted 13 May 2014

Copyright (C) 2014 by author and Scientific Research Publishing Inc. This work is licensed under the Creative Commons Attribution International License (CC BY). http://creativecommons.org/licenses/by/4.0/

(c) (i) Open Access

\begin{abstract}
GRID Alternatives, a non-profit solar contractor, installs solar electric systems for low-income families. Part of GRID Alternatives' program is to provide solar electric systems that are designed to replace $75 \%$ of the homeowners' electricity usage with solar power. This leaves $25 \%$ of their bill still to be paid. In order to save our resources, one must first use conservation practices, then energy efficiency, and then follow-up with renewable energy to cover the rest. GRID Alternatives Inland Empire (GRID IE) educates our participating homeowners and community members on this philosophy. However, measuring whether or not our families have been following this philosophy is hard to prove. It may seem obvious that if we want to know whether our homeowners are saving energy, we should look at their energy usage before and after solar. However, this is not the case with our low-income families that could be using electricity to make their lives more comfortable. GRID IE developed a survey to be given before homeowners received their solar systems and started their participation with GRID Alternatives and the same survey to be given after they have received their solar systems. This before and after survey (pre-test/post-test) asked our homeowners to rate their responses to 7 questions on a scale of $1-10$. The before and after responses for each person were compared, and as a group, their differences were calculated to find out if the differences were statistically significance (within subjects, dependent $Z$ test). 6 out of 7 questions showed statistical significance. The big picture is that change is happening among our low-income homeowners and has happened for many of the varied energy saving methods discussed. It is important to transform energy usage, because the solution is not just solved with solar.
\end{abstract}

\section{Keywords}

Energy Efficiency, Residential, Solar, Survey, Energy Conservation, Water Savings, Low-Income 


\section{Introduction}

There are certain ways to measure energy usage. The most efficient and straight-forward method is to look at one's electric bill and gather their $\mathrm{kW}$, a basic unit of power, and their $\mathrm{kWh}$, the unit of energy that represents power being used over time [1].

Part of GRID Alternatives' program is to provide solar electric systems that are designed to replace $75 \%$ of the homeowners' electricity usage with solar power. This leaves $25 \%$ of their bill still to be paid. GRID Alternatives sees solar power as the solution but not the only one. Protecting earth's resources does not work with a business-as-usual approach, and cannot be saved with replacing one's usage, previously dependent on fossil fuels, with renewable energy $100 \%$ [2]. It is a more wasteful approach and just keeps the status quo. In order to save our resources, one must first use conservation practices, then energy efficiency, and then follow-up with renewable energy to cover the rest [2]. GRID Alternatives Inland Empire (GRID IE), a Southern California regional office working in San Bernardino, Riverside, and Inyo Counties, educates our participating homeowners and community members on this philosophy. However, measuring whether or not our families have been following this philosophy is hard to prove. It may seem obvious that if we want to know if our homeowners are saving, we should look at their energy usage before and after solar. However, our families are low-income and have expressed that they were not previously using their air conditioner and other appliances because they could not afford it. Since receiving solar, our families could have decided to increase their usage of these appliances to live more comfortably.

\section{Methods}

\subsection{Survey}

Here at GRID IE, we developed a method to take qualitative information from our homeowners and use statistics to create quantitative results and give GRID IE a better scope of our work and impact in energy education. We developed a survey to be given before homeowners received their solar systems and started their participation with GRID Alternatives and the same survey to be given after they have received their solar systems. This before and after survey (pre-test/post-test) asked our homeowners to rate their responses to 7 questions on a scale of 1 - 10. The before and after responses for each person were compared, and as a group, their differences were calculated to find out if the differences were statistically significance (within subjects, dependent $\mathrm{Z}$ test) [3]. The questions represented several principles regarding energy conservation and energy efficiency. The questions varied from easy and quick fixes to some more costly options.

\subsection{Statistically Significant}

For something to be statistically significant, it means that the number you get from your sample, when it is compared to a general population, is extremely unlikely to happen by chance and that it happened because of change [3]. There are levels of significance and saying that something happened $100 \%$ due to change is not going to happen. Instead, the typical levels of significance are $10 \%, 5 \%$, and $1 \%$ [3]. 10\% is the lowest level of significance and it means that there was a $10 \%$ probability that the number you received from your sample happened by chance. $5 \%$ is harder to prove, as it means that there is a $5 \%$ probability that the number from your sample happened by chance instead of change. At $1 \%$, there is a $99 \%$ probability that the number did occur by change.

\subsection{Hypothesis \& Tailed Tests}

Typically going into research, you have an idea or a hypothesis about what your results will be. When you have an idea about what the response will be, you will calculate your responses and find significance using a 1-tailed test, meaning that you know your response is either positive or negative, instead of being unsure about the direction [3]. If you just assume there will be change, but you don't know if it's positive or negative, then you use a 2-tailed test. In the research from GRID IE, only 1 of the 7 questions involved a 2-tailed test.

\subsection{Sample Size}

The seven questions asked to our homeowners were sent out to every GRID IE homeowner, in both English and 
Spanish, over 400 families, with only 67 responses back. All 67 responses responded to both the before and the after survey.

\section{Survey Responses}

The survey questions are listed below with our hypothesis on what the response should be and the significance of the response.

\subsection{Question 1: Energy Conservation}

Q1: On a scale of 1 - 10, 1 being never and 10 being always, how often did/do you leave your lights on in a room even if you were/are not in the room?

This question is related to energy conservation. Conserving energy involves changing your behavior to save energy, like turning off your lights when you are not in the room. If our homeowners did participate in this technique, then the responses should show a decrease on this scale. Overall, the results were statistically significant at the 1 -tail, $10 \%$ level. This means that there was a $10 \%$ chance that we got these answers by luck and a $90 \%$ likelihood that these answers represent change.

\subsection{Question 2: Energy Conservation}

Q2: On a scale of 1 - 10, 1 being never and 10 being always, how often did/do you leave your appliances (TV, coffeemaker, computers, etc.) plugged into the wall 24/7?

This question is related to energy conservation and the concept of vampire loads. If you leave an appliance plugged in, like a cell phone charger, but it is not on, it still takes energy from the outlet [4]. By educating our homeowners about vampire loads, the after responses should show a decrease in appliances being plugged in. Overall, the results were significant at the 1-tail, $10 \%$ level. This means that there was a $10 \%$ chance that we got these answers by luck and a $90 \%$ likelihood that these answers represent change.

\subsection{Question 3: Energy Efficiency}

Q3: On a scale of 1 - 10, 1 being none and 10 being all of them, how many of your lights were/are LED or CFLs?

This question is related to energy efficiency. Compact Fluorescent Lamps (CFLs) and Light Emitting Diodes (LEDs) use at least 75\% less energy than other light bulbs [4]. However, these light bulbs have a higher upfront cost and not necessarily something cheap for our homeowners to do. However, with GRID IE's education on switching light bulbs, the responses should show an increase in these lights being used. Overall, this hypothesis showed to be true. Our results were significant at the 1-tail, $5 \%$ level. This means that there was a $5 \%$ chance that we got these answers by luck and a 95\% likelihood that these answers represent change.

\subsection{Question 4: Energy Efficiency}

Q4: On a scale of 1 - 10, 1 being none and 10 being all of them, how many of your appliances were/are ENERGY STAR products?

This question is related to energy efficiency and is highly affected by the age of the current appliances. Appliances older than 10 years old should be replaced and appliances with the ENERGY STAR label use less energy than the other, similar products [4]. This energy saving technique is one of the more expensive methods and could be difficult for our low-income families to do. However, GRID IE has a strong focus in promoting ENERGY STAR, even developing a document about this savings technique. Therefore, the responses should show an increase in ENERGY STAR products being used. Out of all the questions, this is the question with the highest significance level. Our results were significant at the 1-tail, $1 \%$ level. This means that there was a $1 \%$ chance that we got these answers by luck and a 99\% likelihood that these answers represent change.

\subsection{Question 5: Air Conditioning}

Q5: On a scale of 1 - 10, 1 being never and 10 being always, how often did/do you run your air conditioner dur- 
ing the summer?

This question was asked to supplement our general theory about our homeowners not affording their air conditioning before and now using air conditioning since they have solar. However, we did not know if this was the case, so we performed a 2-tailed test, because we do not know if this was a common theme with all of our homeowners. Our results were not significant at any level. However, the value from the calculations was positive, so it highlights that our families were using their air conditioner more, but is not statistically proven. It is enough evidence to verify our suspicions about using kWh alone to highlight energy efficiency and energy use decrease.

\subsection{Question 6: Water Conservation}

Q6: On a scale of 1 - 10, 1 being none and 10 being all of them, how many of your faucets were/are water conserving devices?

Recently, GRID IE has been increasing its involvement in promoting water saving as well as energy savings. They typically go hand-in-hand as it takes energy to heat and pump the water to its final location [5]. The responses should show an increase in water conserving devices, however, our results are not significant at any level. One explanation could be the old sayings "If it's not broken, don't fix it" and "Out of sight, out of mind." Faucets do not typically break and for one to transition to a water conserving device, you would have to go out and buy it. Due to water savings indirect relationship to energy conservation, this technique could be seen as having a lower return on value than switching to an ENERGY STAR product or getting new light bulbs in order to save energy.

\subsection{Question 7: Irrigation}

Q7: On a scale of 1 - 10, 1 being poor and 10 being excellent, how would/do you describe your irrigation watering practices (considering plant material, time of day watering lawn, etc.)?

Irrigation can be a huge waste of water and electricity. If you water your lawn after 7 am and before $7 \mathrm{pm}$, you are exposing your water to the sun, so you have a higher evaporation rate [6]. This means that you would need more water to do the same job and more energy to pump the water. Using correct irrigation practices for the season and region can help save multiple resources. GRID IE dedicates an entire slide on irrigation in the presentations we provide to our homeowners. Therefore, irrigation practices should be increasing. Overall, our results are significant at the 1 -tail, $5 \%$ level. This means that there was a $5 \%$ chance that we got these answers by luck and a $95 \%$ likelihood that these answers represent change.

\subsection{Table 1}

Table 1 gives a quick summarization of the survey responses for the 7 questions.

Table 1. Results of the seven survey questions presented to GRID Alternatives inland empire families.

\begin{tabular}{|c|c|c|c|c|c|c|c|}
\hline Questions & 1 & 2 & 3 & 4 & 5 & 6 & 7 \\
\hline $\begin{array}{c}\text { What was it } \\
\text { about? }\end{array}$ & Light usage & $\begin{array}{l}\text { Appliances } \\
\text { plugged in }\end{array}$ & E.E. lights & $\begin{array}{c}\text { Energy star } \\
\text { products }\end{array}$ & Air conditioner & E.E faucets & Irrigation \\
\hline $\begin{array}{l}\text { What we } \\
\text { expected? }\end{array}$ & Decrease & Decrease & Increase & Increase & Unknown & Increase & Increase \\
\hline Did it happen? & Yes & Yes & Yes & Yes & It increased & Yes & Yes \\
\hline $\begin{array}{c}\text { Was it } \\
\text { Significant? }\end{array}$ & Yes & Yes & Yes & Yes & No & No & Yes \\
\hline $\begin{array}{c}\text { If so, at what } \\
\text { level? }\end{array}$ & $10 \%$ & $10 \%$ & $5 \%$ & $1 \%$ & N/A & N/A & $5 \%$ \\
\hline $\begin{array}{c}\text { If so, } \\
\text { at what tail? }\end{array}$ & 1-tail & 1-tail & 1-tail & 1-tail & Tested at a 2-tail & 1-tail & 1-tail \\
\hline
\end{tabular}




\section{Conclusion}

Although change has been happening, the analysis is limited. It is important to remember that the results represent significant change, but it does not show that GRID IE is the reason for it. There are many other potential reasons for the change, such as, education efforts from other organizations, discounts on prices for appliances, etc. This is a limitation to GRID IE's energy research. Due to time and resource constraints, another limitation in this research is that the pre- and post-test were delivered to our homeowners at the same time. However, the questions were designed to not lead our homeowner to feel like they need to choose higher on the scale. This did not occur on several questions, like question 6 , where the families did not change their behavior and showed this by marking the same answer in both tests. The future scope of GRID IE's research would like to provide the pre-test to our homeowners starting their application then provide them the post-test during their after solar warranty training, a time difference on average of 9 months. However, in the meantime, the big picture is that change is happening among our low-income homeowners and has happened for many of the varied energy saving methods discussed. It is important to transform energy usage, because the solution is not just solved with solar.

\section{References}

[1] (2014) KW and KWh Explained. Understand \& Convert between Power and Energy.

[2] Krieger, S. (2009) Before Adding, Try Reducing. The Wall Street Journal.

[3] Noviello, N. (2008) Secrets of Statistics. 9th Edition, Wiley Custom Services.

[4] Miller, P. (2009) Energy Conservation. National Geographic Magazine.

[5] Gies, E. (2010) Water Conservation to Save Energy. The New York Times, 17 May.

[6] Smith, W.B. (2008) Landscape Irrigation Management Part 5: Irrigation Time of Day. HGIC 1804: Extension: Clemson University, South Carolina. Clemson Cooperative Extension. 